\title{
Hypotonic resistance of boar spermatozoa: sperm subpopulations and relationship with epididymal maturation and fertility
}

\author{
Xavier Druart ${ }^{1,2}$, Jean-Luc Gatti ${ }^{2}$, Sylvie Huet $^{3}$, Jean-Louis Dacheux ${ }^{2}$ and Patrice Humblot ${ }^{1}$ \\ ${ }^{1}$ Union Nationale des Coopératives d'Elevage et d'Insémination Animale, 13 rue Jouet, 94704 Cedex Maisons Alfort, \\ France, ${ }^{2}$ UMR 6175 INRA, CNRS-Université de Tours-Haras Nationaux, Station de Physiologie de la Reproduction et \\ des Comportements, Institut National de la Recherche Agronomique, 37380 Nouzilly, France and ${ }^{3}$ Unité de \\ recherche Mathématiques et Informatique Appliquées, INRA Domaine de Vilvert, 78352 Cedex Jouy-en-Josas, France
}

Correspondence should be addressed to X Druart; Email: xavier.druart@tours.inra.fr

\begin{abstract}
Hypotonic resistance of boar spermatozoa was investigated by measuring the ratio of live/dead spermatozoa (SYBR-14/propidium iodide) by flow cytometry after hypotonic stress. The survival rate of ejaculated spermatozoa incubated in hypotonic solutions ranging from 3 to $330 \mathrm{mmol} / \mathrm{kg}$ followed a sigmoid curve that fitted a simple logistic model. The critical osmolality value (Osm $\left.{ }_{\text {crit }}\right)$ at which $\mathbf{5 0} \%$ of spermatozoa died was determined with this model. Hypotonic resistance of spermatozoa increased with temperature between 15 and $39^{\circ} \mathrm{C}$ and decreased after hydrogen superoxide treatment, but was not modified during 8 days of preservation in Beltsville thawing solution. Hypotonic resistance markedly decreased during epididymal maturation and after ejaculation as $\mathrm{Osm}_{\text {crit }}$ at $15{ }^{\circ} \mathrm{C}$ was $54.7 \pm$ $3.2,68.5 \pm 10.6,116.7 \pm 2.1$ and $194.3 \pm 3.7 \mathrm{mmol} / \mathrm{kg}$ for the caput, corpus, cauda and ejaculated spermatozoa respectively. $\mathrm{Hypo}-$ osmotic stress of $100 \mathrm{mmol} / \mathrm{kg}$ revealed a sperm subpopulation exhibiting increased hypotonic resistance compared with the whole ejaculate $\left(\mathrm{Osm}_{\text {crit }}=67.8 \pm 2.1 \mathrm{mmol} / \mathrm{kg}\right)$. Consistent differences were observed between lean and standard breeds (Pietrain versus Large White) and between boars within the same breed. According to data collected by artificial insemination centers during a large-scale field trial, hypotonic resistance of ejaculates was found to be positively correlated with in vivo fertility.

Reproduction (2009) 137 205-213
\end{abstract}

\section{Introduction}

Owing to volume-regulatory processes, animal cells are able to withstand substantial osmotic stress without permanent damage (Okada et al. 2001, Stutzin \& Hoffmann 2006). When subjected to moderate hypotonic conditions, spermatozoa undergo initial swelling, caused by the entry of external water through the plasma membrane, followed by a decrease in volume to the initial value through a process known as regulatory volume decrease (RVD; Yeung et al. 2006, Petrunkina et al. 2007a). When hypotonic stress overwhelms the RVD process, swelling of the spermatozoa induces coiling of the flagella and ultimately disrupts the plasma membrane, leading to cell death (Curry et al. 2000). Although understanding the metabolic and signaling pathways involved in sperm RVD is increasing (Yeung et al. 2003, 2005, Klein et al. 2006, Petrunkina et al. $2007 \mathrm{~b}$ ), the distinct role of membrane mechanical properties allowing resistance of spermatozoa to hypotonic stress remains to be fully elucidated. The relationship between hypotonic resistance and cryopreservation has been studied intensively (Curry \& Watson 1994, Gilmore et al. 1998, Watson 2000, Petrunkina et al. 2005), but the impact of hypotonic resistance of the membranes of fresh spermatozoa on fertility remains unclear. In a limited study performed in porcine species, the resistance of the acrosomal sperm membrane to breakage under hypotonic conditions was reported to be associated with in vivo fertility (Schilling \& Vengust 1987).

Sperm fertility is acquired during epididymal maturation, together with concomitant modifications of membrane properties such as membrane fluidity and lipid composition (Nikolopoulou et al. 1985, Rana \& Majumder 1990, Rana et al. 1991). Information regarding the changes in hypotonic resistance of spermatozoa during epididymal maturation might help to understand how osmotic resistance may affect fertility. Moreover, spermatozoa are subjected to changes in lipid composition after ejaculation, as well as several stresses such as lipid peroxidation that affects membrane fluidity (Christova et al. 2004, Brouwers et al. 2005), and these may result in decreased fertility after in vitro preservation. Oxidation and long-term preservation might thus 
modify the properties of the sperm membrane and its hypotonic resistance.

The aims of this study were therefore to identify factors affecting the hypotonic resistance of boar spermatozoa and to evaluate the relationship between hypotonic resistance and fertility.

\section{Results}

\section{Modeling of hypotonic resistance of boar spermatozoa}

In order to measure solely the impact of hypotonic resistance on spermatozoa diluted in BTS and stored at $15^{\circ} \mathrm{C}$, the hypotonic media with osmolality ranging from 3 to $330 \mathrm{mmol} / \mathrm{kg}$ were based on BTS and the incubation was performed at $15{ }^{\circ} \mathrm{C}$. The proportion of live boar spermatozoa after incubation at $15{ }^{\circ} \mathrm{C}$ in these media showed a sigmoid curve (Fig. 1). Several nonlinear regression models such as sigmoid, logistic, and Weibull models could also fit this variation. The sigmoid model was chosen because only three parameters had to be calculated with regard to the experimental data available for each curve (see Materials and Methods).

\section{Effects of temperature, oxidation, and storage duration on hypotonic resistance}

Hypotonic resistance was positively correlated with temperature (Fig. 2): Osm $_{\text {crit }}$ was $194.3 \pm 3.7,170.2 \pm$ 3.1 , and $132.9 \pm 4.6 \mathrm{mmol} / \mathrm{kg}$ at 15,25 , and $39^{\circ} \mathrm{C}$ respectively $(P<0.01)$. Lipid peroxidation of spermatozoa was induced in order to evaluate the potential

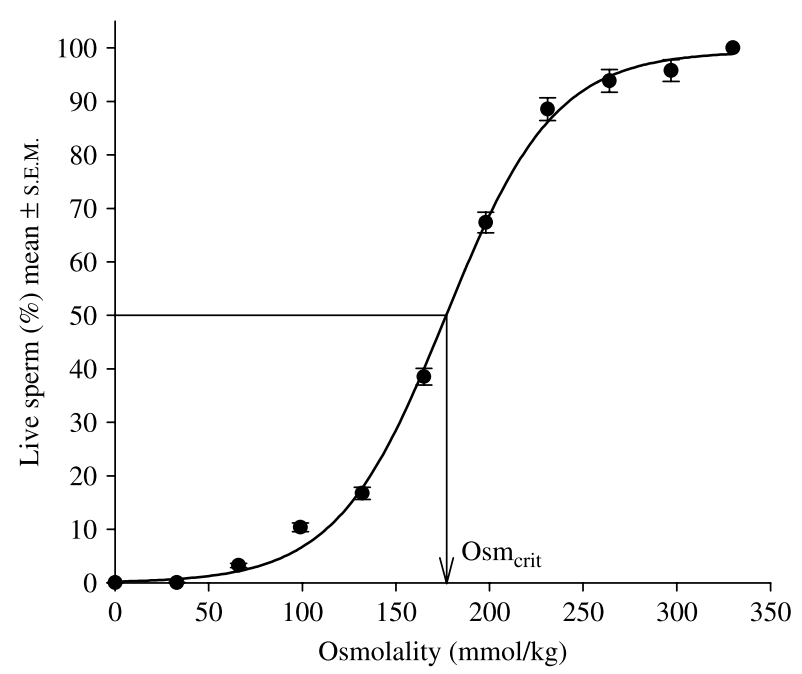

Figure 1 Effects of hypo-osmotic stress on membrane integrity of boarejaculated spermatozoa. Data are presented as percentage of the initial percentage of live cells under iso-osmotic conditions. Error bars not seen are within the symbol. Solid curve shows the logistic model of the percentage of live sperm after hypo-osmotic stress ( $n=12$ boars). Critical osmolality $\left(\mathrm{Osm}_{\text {crit }}\right)$ was defined as the osmolality at which $50 \%$ of the cells died due to osmotic stress and was calculated from the model. relevance of lipids in membrane resistance to hypotonic stress. When hydrogen peroxide was used to produce rapid oxidation of the spermatozoa, the proportion of live spermatozoa in the iso-osmotic medium (BTS) was not different between treatments $(P<0.01)$ but the hypotonic resistance was greatly reduced (Fig. 3). The Osm $_{\text {crit }}$ value increased from $185 \pm 5.3$ to $211 \pm 1.9$, $235 \pm 3.9$, and $248 \pm 3.9 \mathrm{mmol} / \mathrm{kg}$ for $0,0.1,1$, and $10 \mathrm{mM}$ hydrogen peroxide respectively $(P<0.01)$. By contrast, the hypotonic resistance of ejaculated spermatozoa was not significantly modified after $0,1,3$, and 8 days of storage in BTS at $15{ }^{\circ} \mathrm{C}(199 \pm 4.6,195.1 \pm 4.7$, $196.5 \pm 10.0$, and $196.5 \pm 9.6 \mathrm{mmol} / \mathrm{kg}$ respectively).

\section{Hypotonic resistance and epididymal maturation}

Epididymal maturation was associated with a significant decrease in hypotonic resistance (Fig. 4): Osm crit was $54.7 \pm 3.2$ for caput spermatozoa, and increased to $68.5 \pm 10.6$ for the corpus and $116.7 \pm 2.1 \mathrm{mmol} / \mathrm{kg}$ for the cauda $(P<0.01)$. Hypotonic resistance was further decreased after ejaculation, reaching an $\mathrm{Osm}_{\text {crit }}$ of $194.3 \pm 3.7 \mathrm{mmol} / \mathrm{kg}$ for ejaculated spermatozoa.

\section{Isolation of a subpopulation of spermatozoa which increased hypotonic resistance}

Boar spermatozoa were diluted in control iso-osmotic medium $(330 \mathrm{mmol} / \mathrm{kg}$ ) and subjected to hypotonic stress at $100 \mathrm{mmol} / \mathrm{kg}$ at $15{ }^{\circ} \mathrm{C}$. The proportion of live spermatozoa after $25 \mathrm{~min}$ was $87.7 \pm 2.6 \%$ in control medium and $19.6 \pm 1.5 \%$ in $100 \mathrm{mmol} / \mathrm{kg}$ medium.

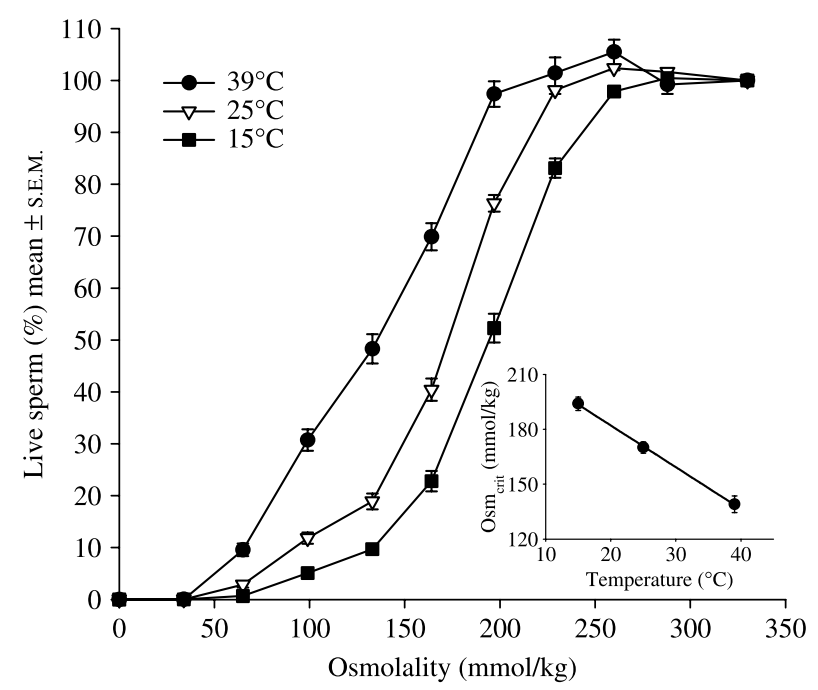

Figure 2 Effects of temperature on hypotonic resistance of ejaculated spermatozoa. Spermatozoa were subjected to hypo-osmotic stress at 15,25 , and $39^{\circ} \mathrm{C}$. Data are presented as the percentage of the initial percentage of live cells under iso-osmotic conditions ( $n=13$ boars). Critical osmolality $\left(\mathrm{Osm}_{\text {crit }}\right)$ was linearly dependent on temperature between $15^{\circ} \mathrm{C}$ and $37^{\circ} \mathrm{C}$ 


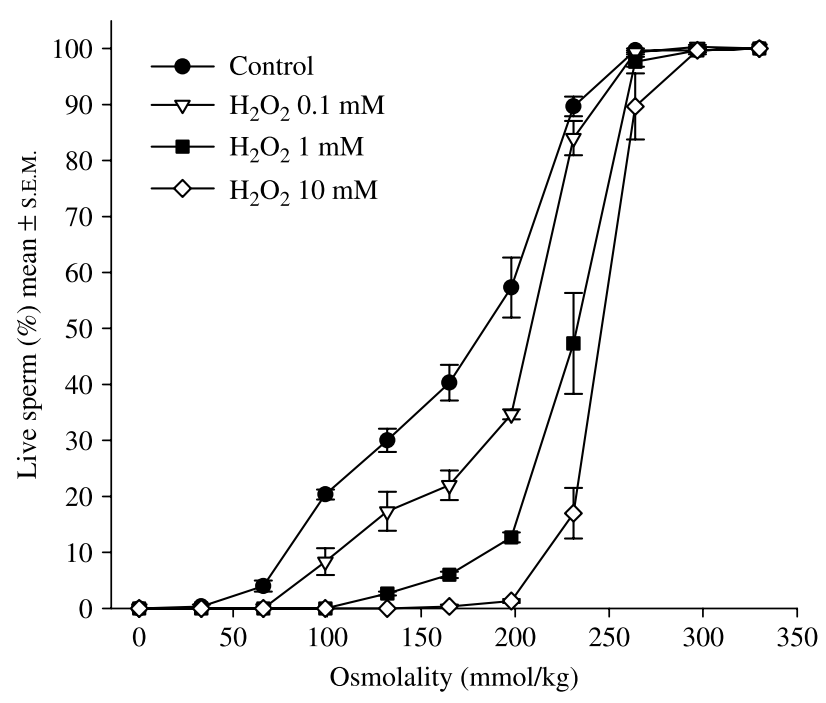

Figure 3 Effects of oxidation on hypotonic resistance of ejaculated spermatozoa. Spermatozoa were incubated with hydrogen peroxide $(0.1,1$, and $10 \mathrm{mM})$ and subjected to hypo-osmotic stress at $15{ }^{\circ} \mathrm{C}$. Data are presented as the percentage of the initial percentage of live cells under iso-osmotic conditions ( $n=3$ boars).

After incubation, live spermatozoa were sorted by flow cytometry based on live/dead staining with SYBR-14/PI and returned to iso-osmotic conditions. The proportions of live spermatozoa for the live sorted population were $99.7 \pm 0.1 \%$ and $97.6 \pm 0.4 \%$ in control and hypotonic conditions respectively. After the re-equilibration step in iso-osmotic conditions, sorted spermatozoa were again subjected to hypotonic stress over the $3-330 \mathrm{mmol} / \mathrm{kg}$

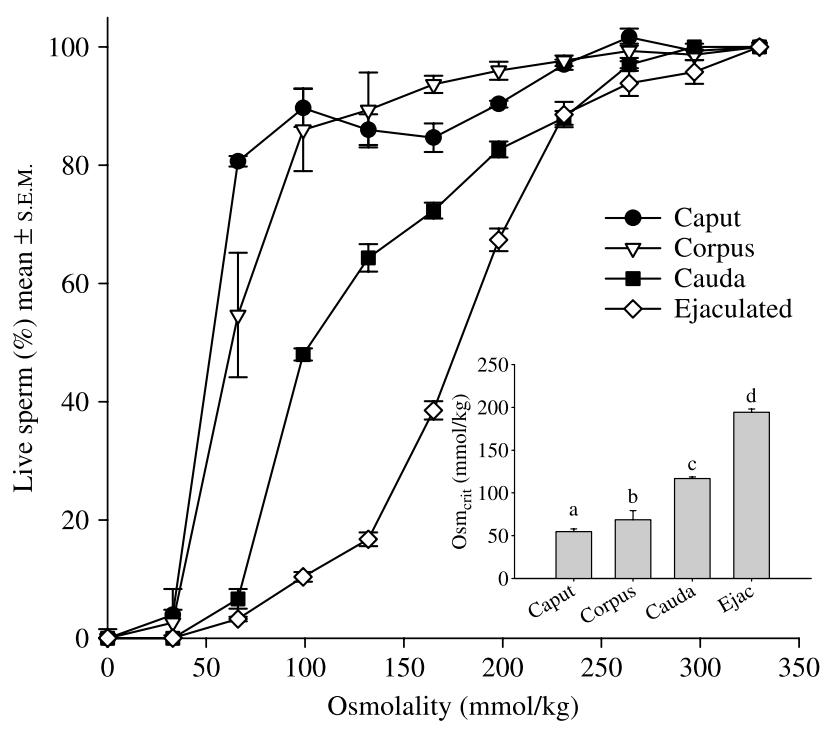

Figure 4 Effects of epididymal maturation on hypotonic resistance. Epididymal spermatozoa from caput, corpus, and cauda regions, and ejaculated spermatozoa were subjected to hypo-osmotic stress at $15^{\circ} \mathrm{C}$. Data are presented as the percentage of the initial percentage of live cells under iso-osmotic conditions ( $n=3$ boars). Critical osmolality (Osm crit) increased during epididymal maturation and after ejaculation. Values with different letters $(\mathrm{a}, \mathrm{b}, \mathrm{c}, \mathrm{d})$ are significantly different $(P<0.05)$. range of osmolality (Fig. 5). The control spermatozoa (330 $\mathrm{mmol} / \mathrm{kg}$-sorted) exhibited the typical sigmoid evolution as a function of osmolality $\left(\mathrm{Osm}_{\text {crit }}=186.7 \pm\right.$ $6.0 \mathrm{mmol} / \mathrm{kg}$ ), while the spermatozoa sorted for their hypotonic resistance $(100 \mathrm{mmol} / \mathrm{kg}$-sorted) were not affected between 330 and $100 \mathrm{mmol} / \mathrm{kg}(P<0.01)$, showing that this subpopulation was much more resistant to hypotonic stress $\left(\mathrm{Osm}_{\mathrm{crit}}=67.8 \pm 2.1 \mathrm{mmol} / \mathrm{kg}\right)$.
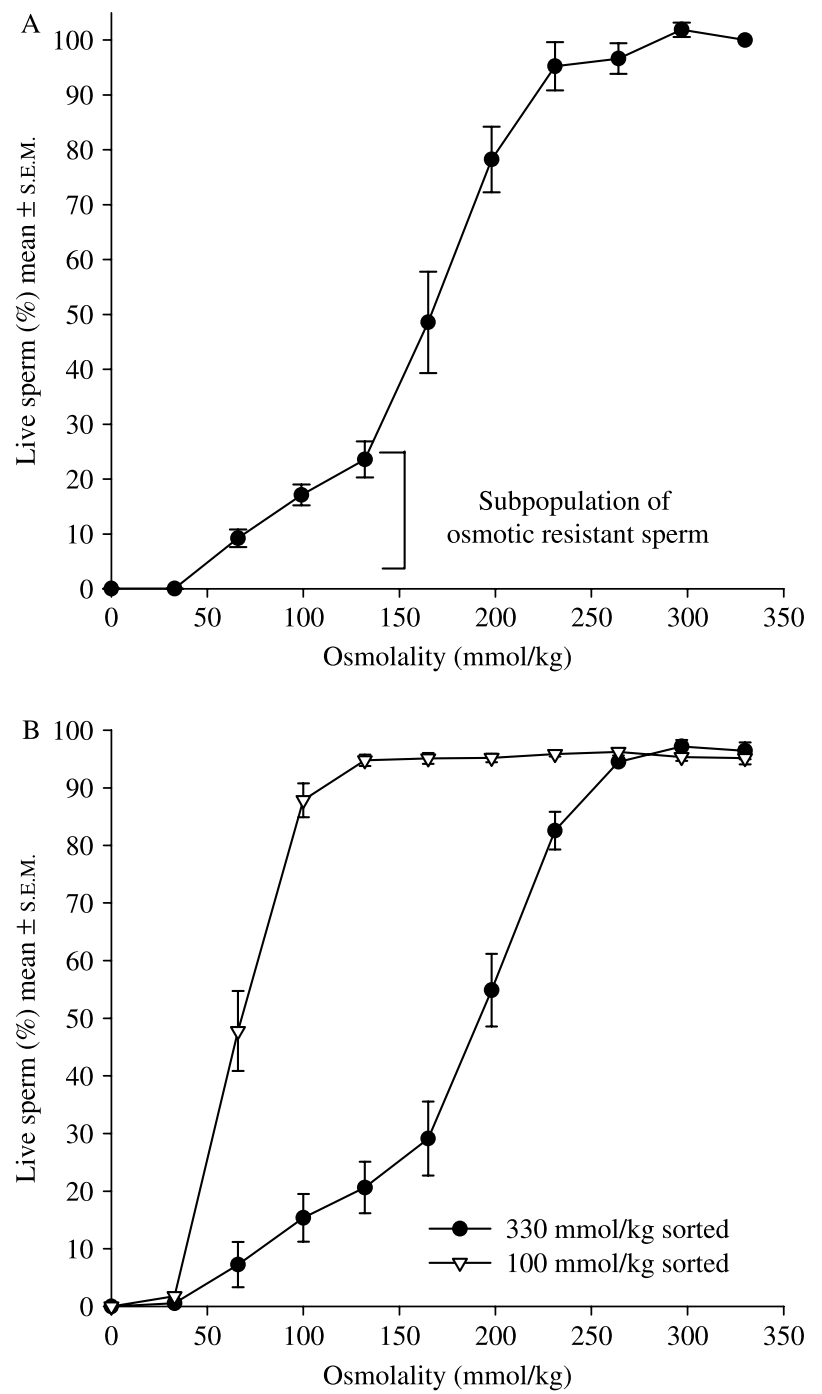

Figure 5 Identification of a subpopulation of ejaculated spermatozoa with increased hypotonic resistance. (A) Effects of hypo-osmotic stress on sperm membrane integrity. Example of representative individual boar showing the subpopulation of spermatozoa with increased hypotonic resistance ( $n=3$ ejaculates). Data are presented as the percentage of the initial percentage of live cells under iso-osmotic conditions. (B) Live spermatozoa were sorted by FACS after iso-osmotic incubation at $330 \mathrm{mmol} / \mathrm{kg}$ (330 mmol/kg-sorted) or after initial hypoosmotic stress at $100 \mathrm{mmol} / \mathrm{kg}$ (100 mmol/kg sorted). These two populations of live spermatozoa were then re-equilibrated in the isoosmotic buffer $(330 \mathrm{mmol} / \mathrm{kg})$ and subjected to further hypo-osmotic stress over the complete $0-330 \mathrm{mmol} / \mathrm{kg}$ range. Data presented are raw percentages of live spermatozoa after sorting and the second hypoosmotic stress ( $n=4$ boars). 


\section{Effects of breed}

Genetic origin affected the hypotonic resistance of spermatozoa (Fig. 6): spermatozoa from Pietrain boars showed greater hypotonic resistance than Large White boars $\left(\mathrm{Osm}_{\text {crit }}=148.6 \pm 2.3\right.$ vs $188.4 \pm 1.2 \mathrm{mmol} / \mathrm{kg}$ respectively, $n=48$ and $n=77, P<0.01)$.

\section{Hypotonic resistance and fertility}

The relationship between hypotonic resistance and fertility of the spermatozoa was evaluated during a field trial involving 11 Pietrain boars and 922 Pietrain sows housed in 12 different commercial farms. After correction for the farm effect, farrowing rate and litter size were not significantly different between boars. No significant correlation was observed between the mean hypotonic resistance value for each boar and fertility (farrowing rate and litter size). The relationship between hypotonic resistance and fertility was further investigated after grouping the total of 133 ejaculates into classes according to their $\mathrm{Osm}_{\text {crit. }}$. The ejaculates were grouped in three classes, with $\mathrm{Osm}_{\text {crit }}>170 \mathrm{mmol} / \mathrm{kg}$ for class 1, between 150 and $170 \mathrm{mmol} / \mathrm{kg}$ for class 2, and $<150 \mathrm{mmol} / \mathrm{kg}$ for class 3. Mean Osm crit $_{\text {was }} 191.3 \pm$ $0.8,160.5 \pm 0.4$, and $128.8 \pm 1.4 \mathrm{mmol} / \mathrm{kg}$ for classes 1 , 2 , and 3 respectively. Although litter size was not significantly different between classes, the farrowing rate was significantly different $(P<0.05)$, being $88.7 \pm$ $3.6,92.1 \pm 3.0$, and $95.4 \pm 2.4 \%$ for classes 1,2 , and 3 respectively (Fig. 7 ). Sperm viability and mobility were not significantly different between classes.

\section{Discussion}

In our experimental conditions, the hypotonic resistance of boar spermatozoa was evaluated by the resistance of the plasma membrane to rupture in hypotonic media. Between 3 and $330 \mathrm{mmol} / \mathrm{kg}$, the proportion of spermatozoa showing intact membranes was not linearly related to osmotic pressure. Instead, the hypotonic resistance followed a curve that was appropriately fitted by several non-linear models. Models such as sigmoid, logistic or Weibull models, often used for failure analysis (Weibull 1951), could be used for fitting the rupture resistance of the boar sperm membrane. The logistic model was chosen because only a limited number of parameters were needed to fit the experimental curves. This modelization therefore allowed the use of a single value, $\mathrm{Osm}_{\text {crit, }}$ defined as the osmolality at which $50 \%$ of the spermatozoa remain alive (Noiles et al. 1997) and which, in the case of this logistic curve, is the $x$-coordinate of the curve point of inflexion. This parameter was used throughout the study to summarize the logistic curve and to study the impact of several factors on hypotonic resistance.

Hypotonic resistance was linearly dependent on incubation temperatures between 15 and $39{ }^{\circ} \mathrm{C}$. It has been shown that the fluidity of the plasma membrane of boar spermatozoa increases with temperature (Canvin \& Buhr 1989). The increase in hypotonic resistance could be explained by increased fluidity and greater ability of spermatozoa to tolerate swelling. This is also supported by the fact that oxidative treatment of spermatozoa with cumene hydroperoxide has been shown to reduce the diffusion of membrane lipids (Christova et al. 2004), and in our study hydroperoxide also decreased hypotonic resistance. The genetic impact on hypotonic resistance observed between the Pietrain breed and the Large White breed might also be related to the composition of sperm lipids since Pietrain boars are leaner than Large White boars (Quinious \& Noblet 1995). The relationship between the body lipid composition and the sperm lipid composition in these two breeds has not yet been established, but it can be hypothesized that these breeds produce spermatozoa with different lipid compositions and hence different physical properties. Our findings showed clearly a progressive decrease in the hypotonic resistance of boar spermatozoa during their transit from
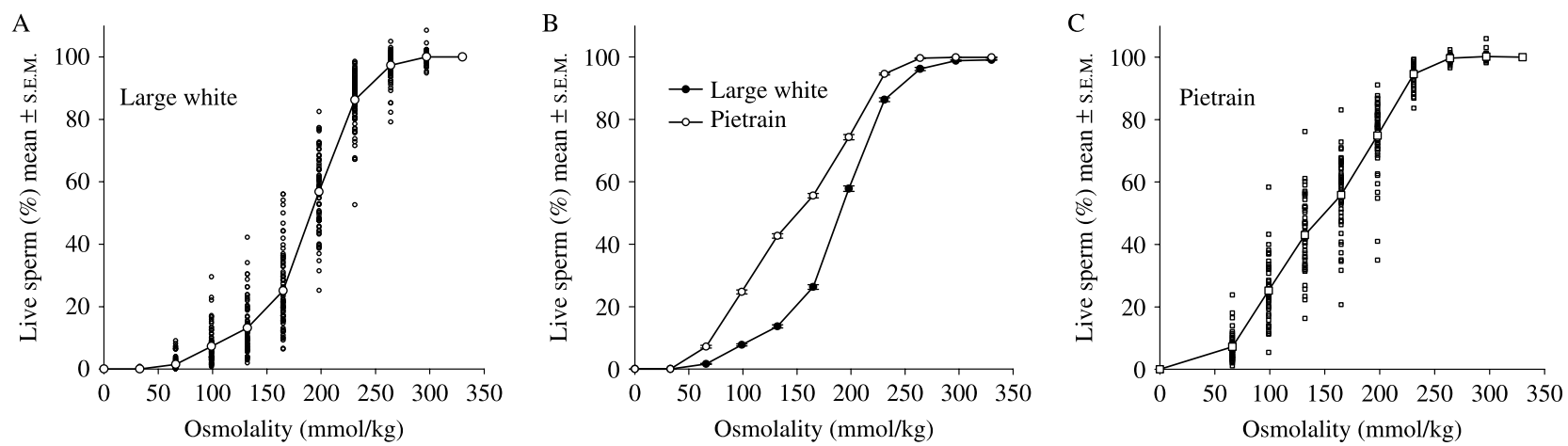

Figure 6 Effects of breed on hypotonic resistance of ejaculated spermatozoa. Semen from Large White and Pietrain boars were subjected to hypoosmotic stress at $15{ }^{\circ} \mathrm{C}$. Data are presented as the percentage of the initial percentage of live cells under iso-osmotic conditions. (A) Large White breed ( $n=77$ boars). Each spot is the mean value for one boar (two ejaculates per boar). (B) Comparison of Large White and Pietrain breeds. (C) Pietrain breed ( $n=48$ boars). 


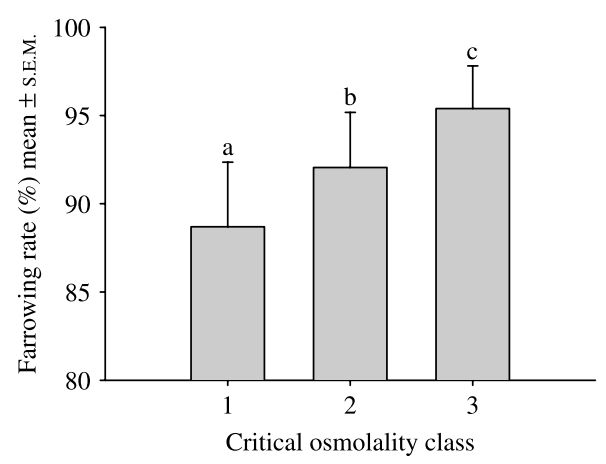

Figure 7 Effects of hypotonic resistance on fertility of ejaculated spermatozoa. Values represent farrowing rate for three classes of ejaculates with different critical osmolality. Hypotonic resistance of sperm was positively correlated with in vivo fertility as low critical osmolality was associated with high farrowing rate. Osm $_{\text {crit }}$ was over $170 \mathrm{mmol} / \mathrm{kg}$ for class 1 , between 150 and $170 \mathrm{mmol} / \mathrm{kg}$ for class 2, and less than $150 \mathrm{mmol} / \mathrm{kg}$ for class 3 . Values with different letters $(\mathrm{a}, \mathrm{b}, \mathrm{c})$ are significantly different $(P<0.05)$.

the caput to the cauda of the epididymis. The resistance of osmotically swollen spermatozoa to rupture by detergent was reported to be higher for caput than cauda spermatozoa in the ram (Schweisguth \& Hammerstedt 1992), and higher hypotonic resistance was also reported for caput than cauda spermatozoa in the kangaroo (McClean et al. 2006). During epididymal maturation, boar spermatozoa undergo modifications of lipid membrane composition (Evans \& Setchell 1979, Nikolopoulou et al. 1985) and this lipid membrane remodeling leads to the appearance of domains with different diffusional properties (James et al. 1999, Bruckbauer et al. 2007, Jones et al. 2007). During this epididymal transit, spermatozoa also undergo changes in protein composition related to sequential changes in epididymal fluid proteins due to epididymal epithelium secretion (Dacheux et al. 1989, 1998, 2005, Syntin et al. 1996). Decreases in hypotonic resistance during epididymal maturation could thus be associated with these changes in lipid and protein compositions, resulting in different physical properties of the membrane.

We observed that hypotonic resistance of boar spermatozoa was markedly reduced after ejaculation. During ejaculation, large amounts of boar seminal plasma proteins, such as spermadhesins, bind to the sperm membrane (Dostalova et al. 1994, Jonakova et al. 2000). Bull seminal plasma protein PDC 109, related to spermadhesins, binds with high affinity to sperm membrane lipids (Ramakrishnan et al. 2001, Tannert et al. 2007) and decreases the mobility of spin-labeled phospholipids in epididymal sperm membranes (Greube et al. 2001). SP $1 / 2$, a stallion seminal plasma protein related to PDC 109, also induces immobilization of epididymal sperm phospholipids (Greube et al. 2004). Bovine seminal plasma proteins, such as NPC2, induce cholesterol efflux from cauda epididymal spermatozoa and affect the combination of lipids and membrane proteins (Girouard et al. 2008). The role of seminal plasma proteins on hypotonic resistance remains to be fully determined, but the coating of seminal proteins on epididymal spermatozoa might decrease hypotonic resistance through a decrease in fluidity of the sperm membrane lipid phase. Taken together, our results suggest that the hypotonic resistance of boar spermatozoa at $15^{\circ} \mathrm{C}$ could be explained by mechanical properties of the membrane related to membrane fluidity.

Evidence of a subpopulation of spermatozoa with increased hypotonic resistance has already been suggested by repeated hypotonic stress on ram spermatozoa, showing that the proportion of live spermatozoa stabilized after the first osmotic stress (Curry \& Watson 1994). The distribution of boar sperm volume after moderate hypotonic stress also suggested sperm subpopulations (Petrounkina et al. 2000). Our study revealed the existence in the boar ejaculate of a subpopulation of spermatozoa resistant to hypotonic stress at $15{ }^{\circ} \mathrm{C}$. We hypothesized the existence of this subpopulation when the proportion of live spermatozoa observed after incubation in $60-100 \mathrm{mmol} / \mathrm{kg}$ media was always higher than expected with non-linear models. The resistant spermatozoa could then be effectively separated by cell sorting from the other populations and could withstand subsequent hypotonic stress without affecting their viability. The mechanisms underlying this hypotonic resistance are unknown, but it could be hypothesized that these spermatozoa might have a different lipid composition resulting in increased membrane fluidity, as a subpopulation of boar spermatozoa with a lower cholesterol/phospholipids ratio has been described (Flesch et al. 2001). It is of note that the resistant subpopulation was only observed for ejaculated spermatozoa and not for epididymal spermatozoa. The effects of the interaction between seminal plasma and epididymal spermatozoa might vary according to different epididymal sperm subpopulations. The increased hypotonic resistance of this subpopulation could therefore be explained as being a consequence of a different interaction of seminal plasma with an epididymal subpopulation with distinct properties.

Throughout this study, several boars with spermatozoa showing extremes of hypotonic resistance (high or low) were used weekly over long periods ( 1 or 2 years) and they always exhibited the expected hypotonic resistance, despite the fact that variations in viability and motility were observed. Moreover, during the fertility study (which extended over 13 weeks), the hypotonic resistance of extreme Pietrain boars remained without significant variation between 13 consecutive ejaculates, and this parameter appears to be a consistent semen characteristic which is male dependent.

The relationship between boar semen quality and fertility has been widely documented, (Rodriguez-Martinez 2006) without consensus regarding effective fertility predictors. In commercial sow farms, the 
prediction of fertility by semen parameters is limited by the use of high numbers of spermatozoa per dose and high quality of semen (Gadea et al. 2004). As we observed that hypotonic resistance showed greater repeatability and variability among artificial insemination (AI) boars than classical criteria, the aim of the fertility trial was first to characterize boars on their hypotonic resistance and then to relate this parameter to fertility. Despite the scale of this trial, and probably because of the high standard of $\mathrm{Al}$ conditions ( $3 \mathrm{Al}$ per cycle with $3.10^{9}$ of spermatozoa showing $80 \%$ normal morphology and motility) and the design of the trial correctly evaluating farm and parity effects, no significant difference in fertility was found between males. However, when ejaculates were grouped by class according to their hypotonic resistance, we were able to demonstrate a significant positive correlation between hypotonic resistance and fertility, even in the narrow range of $85-95 \%$ farrowing rate.

The mechanisms underlying the relationship between hypotonic resistance and fertility remain unclear. It has been proposed that the ability to regulate sperm volume through RVD processes in the female genital tract is important for fertility because spermatozoa undergo hypotonic stress due to the lower osmolality of uterine fluid compared with those of cauda epididymal fluid and seminal plasma (Yeung \& Cooper 2001). Indeed, RVD has been reported to be associated with in vivo fertility in boar species (Petrunkina et al. 2004). Although it has been reported that the RVD process was acquired together with fertilizing ability during mouse epididymal maturation (Yeung et al. 2002), this study clearly showed that hypotonic resistance decreased during the epididymal maturation in the boar. Different mechanisms could possibly be involved, as accumulation of osmolytes could be involved in the acquisition of RVD during maturation (Yeung et al. 2004). Our findings also suggest that the decrease in hypotonic resistance might be associated with structural changes in the sperm membrane. The relationship between RVD and the hypotonic resistance measured in our conditions, based on mechanical resistance of the membrane to rupture, require further investigation and suggest the use of this parameter as a fertility predictor in the boar.

\section{Materials and Methods \\ Reagents and media}

The live/dead sperm viability kit was obtained from Molecular Probes (Eugene, OR, USA). All chemicals were of reagent grade and purchased from Sigma. The medium used was BTS (Beltsville Thawing Solution extender) and hypo-osmotic solutions were prepared by diluting iso-osmotic BTS $(330 \mathrm{mmol} / \mathrm{kg}$ ) with Millipore purified water $(3 \mathrm{mmol} / \mathrm{kg})$ to produce solutions of $3-330 \mathrm{mmol} / \mathrm{kg}$. Actual media osmolalities were determined with a vapor osmometer (VAPRO,
Westcor Inc., Logan, UT, USA) and osmolalities were accurate to $\pm 3 \mathrm{mmol} / \mathrm{kg}$.

\section{Animals and semen collection}

Large White and Pietrain boars were housed under standard conditions. Semen was collected by masturbation using the gloved-hand technique. The whole ejaculate was collected and filtered through gauze. Semen was diluted in $35^{\circ} \mathrm{C}$ BTS at $3.10^{7}$ spermatozoa per $\mathrm{ml}$, packaged in $100 \mathrm{ml}$ insemination doses in plastic bottles, and allowed to cool at $15^{\circ} \mathrm{C}$. All ejaculates showed high motility ( $>80 \%$ progressive motile spermatozoa) and normal morphology ( $>80 \%$ normal spermatozoa). Epididymides were obtained from three adult Large White boars. Spermatozoa from the different epididymal regions (caput, corpus and cauda) were collected by microperfusion (Dacheux 1980).

\section{Assessment of motility}

Sperm motility was determined after $10 \mathrm{~min}$ incubation at $37{ }^{\circ} \mathrm{C}$ using a computer-assisted analysis system (HamiltonThorn, Beverly, MA, USA). A $2 \mu$ l aliquot was transferred to a preheated slide and a minimum of 300 cells were analyzed over 10 fields. Spermatozoa were classified as progressive spermatozoa when VAP $>80 \mu \mathrm{m} / \mathrm{s}$ and $\mathrm{LIN}>60$.

\section{Flow cytometric assessment of hypotonic resistance}

The osmotic resistance of spermatozoa was estimated by the proportion of cells with intact plasma membranes after $20 \mathrm{~min}$ incubation in a hypo-osmotic medium. Aliquots of BTS-diluted semen $\left(33 \mu \mathrm{l}, 3.10^{7}\right.$ cell $\left.\mathrm{s} / \mathrm{ml}\right)$ were transferred into $1 \mathrm{ml}$ iso- or hypo-osmotic BTS solution, ranging from 3 to $330 \mathrm{mmol} / \mathrm{kg}$, containing $10 \mu \mathrm{l} \mathrm{SYBR}-14$ at $10 \mu \mathrm{g} / \mathrm{ml}$ (final concentration of $100 \mathrm{ng} / \mathrm{ml}$ ), and $2 \mu \mathrm{l}$ propidium iodide at $2 \mathrm{mg} / \mathrm{ml}$ (final concentration of $4 \mu \mathrm{g} / \mathrm{ml}$ ). SYBR-14 stained the nuclei of living spermatozoa bright green whereas PI stained red only dead spermatozoa that had lost their membrane integrity (Garner \& Johnson 1995). The proportions of live/dead spermatozoa exhibiting SYBR-14 (green) and PI (red) fluorescence respectively were measured with an EPICS-XL flow cytometer (BeckmanCoulter, Villepinte, France) using an air-cooled argon laser operating at $488 \mathrm{~nm}$ and $15 \mathrm{~mW}$. Forward scattering and side scattering were recorded to define the size characteristics and provide gating parameters for selection of the sperm population. A minimum of $10^{4}$ cells was counted for each analysis.

\section{Determination of Osm $_{\text {crit }}$}

Critical osmolality $\left(\mathrm{Osm}_{\text {crit }}\right)$ was defined as the osmolality at which $50 \%$ of the cells died due to osmotic stress (Noiles et al. 1997) and was used as a parameter to characterize the osmotic resistance of the whole sperm population. This parameter was calculated from a sigmoid function model describing the relationship between sperm viability and osmolality by three parameters:

$Y=b_{0} /\left(1+\left(e^{\left(-\left(\mathrm{OS}-b_{2}\right)\right)}\right) / b_{1}\right)$ 
where $Y$ is the percentage of live spermatozoa normalized to the percentage of live spermatozoa in control iso-osmotic medium and OS is the osmolality. The three parameters $\left(b_{0}, b_{1}\right.$, and $\left.b_{2}\right)$ were calculated using the NLIN procedure of the SAS package (SAS Institute, Cary, NC, USA). Osm crit was then determined using the above described model and calculated as:

$$
\mathrm{Osm}_{\text {crit }}=b_{2}-b_{1} \log \left(\left(b_{0}-50\right) / 50\right)
$$

This non-linear model and the calculation of $\mathrm{Osm}_{\text {crit }}$ were validated using the first set of data generated from the analysis of hypotonic resistance at $15^{\circ} \mathrm{C}$ of semen collected from 12 Large White boars.

\section{Effects of several physical environmental and animal parameters on sperm hypotonic resistance}

To evaluate the effects of temperature, incubation of spermatozoa in iso- and hypo-osmotic media (3-330 mmol/kg) was performed at 15,25 , and $39{ }^{\circ} \mathrm{C}$ in incubators. The hypotonic resistance of boar spermatozoa was analyzed during long-term preservation. BTS-diluted spermatozoa were stored at $15{ }^{\circ} \mathrm{C}$ for 8 days (Day $0=$ collection day) and hypotonic resistance was assessed at $15{ }^{\circ} \mathrm{C}$ on days $0,1,3$, and 8 . The influence of oxidation status of spermatozoa was estimated by the addition of hydrogen peroxide to BTS-diluted spermatozoa $\left(3.10^{7} / \mathrm{ml}\right)$ at final concentrations of $0.1,1$, and $10 \mathrm{mM}$, and spermatozoa were incubated overnight at $15^{\circ} \mathrm{C}$. Hypotonic resistance was then assessed at $15^{\circ} \mathrm{C}$.

The influence of the genetic origin of boars on osmotic resistance was studied in Large White boars and Pietrain boars housed under identical conditions in one commercial semen production center (Cobiporc, St Gilles, France). Hypotonic resistance was analyzed for 158 ejaculates from 77 Large White boars and 98 ejaculates from 48 Pietrain boars. Individual differences between males and ejaculates were further investigated in 11 Pietrain boars from which semen was collected once a week for 15 weeks, and hypotonic resistance was assessed at $15{ }^{\circ} \mathrm{C}$.

\section{Flow cytometric sorting of spermatozoa with increased hypotonic resistance}

Flow cytometric sorting was used to separate spermatozoa with increased hypotonic resistance from the whole spermatozoa population. BTS-diluted semen $(300 \mu \mathrm{l})$ was transferred and incubated for $20 \mathrm{~min}$ at $15^{\circ} \mathrm{C}$ either in $10 \mathrm{ml}$ BTS (330 mmol/kg-treated sample) or in $10 \mathrm{ml}$ hypo-osmotic solution (100 mmol/kg-treated sample). Both solutions contained SYBR-14 $(100 \mathrm{ng} / \mathrm{ml})$ and PI $(4 \mu \mathrm{g} / \mathrm{ml})$. At the end of the incubation period, spermatozoa from $330 \mathrm{mmol} / \mathrm{kg}$ treated samples and $100 \mathrm{mmol} / \mathrm{kg}$-treated samples were subjected to flow cytometric analysis. Live spermatozoa, i.e. SYBR-positive and PI-negative spermatozoa, were identified and sorted on the basis of their green fluorescence. Sorted sperm from both samples were returned to iso-osmotic conditions by collection after sorting in a $15 \mathrm{ml}$ conical tube containing $5 \mathrm{ml}$ BTS $(330 \mathrm{mmol} / \mathrm{kg})$. The Cell sorter, an ALTRA cell sorter (Beckman-Coulter) with EXPO32 software, operated at low pressure (12 psi) and moderate sorting rate (1000 cell/s) to assure high purity and maximum preservation of integrity after sorting. $10^{7}$ live spermatozoa were sorted from $330 \mathrm{mmol} / \mathrm{kg}$ and $100 \mathrm{mmol} / \mathrm{kg}$-treated samples. Sorted spermatozoa were then centrifuged (800 g, $5 \mathrm{~min}$ ) and the pellet was gently re-suspended in $1 \mathrm{ml}$ BTS. To check the efficiency of sorting, a $10 \mu \mathrm{l}$ aliquot was immediately transferred to a $1 \mathrm{ml}$ BTS tube and live/dead proportions were determined using the same flow cytometric procedure. The hypotonic resistance of live spermatozoa sorted from $330 \mathrm{mmol} / \mathrm{kg}$ and $100 \mathrm{mmol} / \mathrm{kg}$ treated samples was then measured. Live sorted spermatozoa were subjected to further hypotonic stress by transferring $10 \mu \mathrm{l}$ aliquots to a series of tubes containing $1 \mathrm{ml}$ BTS hypo-osmotic solution (3-330 mmol/kg) with SYBR/PI. After $20 \mathrm{~min}$ incubation at $15{ }^{\circ} \mathrm{C}$, sperm membrane integrity was again assessed with the previously described flow cytometric procedure.

\section{Hypotonic resistance and fertility}

A fertility trial was designed to study the relationship between hypotonic resistance of spermatozoa and fertility. Semen was collected weekly over a 15-week period from 11 Pietrain boars housed in a commercial artificial insemination center. Doses of $3.10^{9}$ total spermatozoa were produced and one dose per ejaculate was sent to the laboratory in isothermal boxes at $15{ }^{\circ} \mathrm{C}$ where motility and hypotonic resistance were assessed. A total of 133 ejaculates were used to inseminate 922 sows housed in 12 different farms under commercial management. Sows showing estrus 4 days after weaning were inseminated thrice: after the detection of standing heat and 12 and $24 \mathrm{~h}$ later. Sows ranged in parity from 2 to 11 .

\section{Statistical analyses}

Statistical analyses were carried out using the SAS software (SAS Institute, USA). The percentage of intact spermatozoa in a given sample after exposure to hypo-osmotic media was normalized to the percentage of intact spermatozoa of the same sample in iso-osmotic control medium. This normalized percentage of intact spermatozoa was subjected to arc sine transformation and analyzed by standard ANOVA procedures using the GLM procedure in SAS software. Differences between $\mathrm{Osm}_{\text {crit }}$ determinations were obtained by the same procedures.

In order to assess only the effects of semen quality on fertility, the fertility trial was designed to evaluate side effects, such as farm and parity. Data collected included any observations at insemination, parity, insemination times and dates, farrowing, total litter size, number of live piglets born, dates of return to estrus or abortion, death or culling.

Fertility data were analyzed with a general linear model (GENMOD) for an estimation of the effects of farm, parity, boar, and ejaculate parameters on fertility. Ejaculates were grouped in 3 classes according to their Osm $_{\text {crit }}$. Individual farrowing data for each sow were linked with a logit link to the other terms of the model, including the farm, boar, and Osm crit $_{\text {class. }}$ Litter size was introduced with a linear link in the same model including parity, boar, and Osm crit $_{\text {class. }}$ 


\section{Declaration of interest}

The authors declare there is no conflict of interest that would prejudice the impartiality of this scientific study.

\section{Funding}

This study was supported by funds from INRA and UNCEIA.

\section{Acknowledgements}

The authors wish to thank the AI Cooperative Cobiporc (France) for providing boar semen and fertility data, Eli Sellem and Guillaume Tsikis for their technical assistance in sperm evaluation, and Doreen Raine for the revision of the English language of the manuscript.

\section{References}

Brouwers JF, Silva PFN \& Gadella BM 2005 New assays for detection and localization of endogenous lipid peroxidation products in living boar sperm after BTS dilution or after freeze-thawing. Theriogenology 63 458-469.

Bruckbauer A, James P, Zhou D, Yoon JW, Excell D, Korchev Y, Jones R \& Klenerman D 2007 Nanopipette delivery of individual molecules to cellular compartments for single-molecule fluorescence tracking. Biophysical Journal 93 3120-3131.

Canvin AT \& Buhr MM 1989 Effect of temperature on the fluidity of boar sperm membranes. Journal of Reproduction and Fertility 85 533-540.

Christova Y, James P \& Jones R 2004 Lipid diffusion in sperm plasma membranes exposed to peroxidative injury from oxygen free radicals. Molecular Reproduction and Development 68 365-372.

Curry MR \& Watson PF 1994 Osmotic effects on ram and human sperm membranes in relation to thawing injury. Cryo Letters 31 39-46.

Curry MR, Kleinhans FW \& Watson PF 2000 Measurement of the water permeability of the membranes of boar, ram, and rabbit spermatozoa using concentration-dependent self-quenching of an entrapped fluorophore. Cryo Letters 41 167-173.

Dacheux JL 1980 An in vitro perfusion technique to study epididymal secretion. IRCS Medical Science 8137.

Dacheux JL, Dacheux F \& Paquignon M 1989 Changes in sperm surface membrane and luminal protein fluid content during epididymal transit in the boar. Biology of Reproduction $\mathbf{4 0}$ 635-651.

Dacheux JL, Druart X, Fouchecourt S, Syntin P, Gatti JL, Okamura N \& Dacheux F 1998 Role of epididymal secretory proteins in sperm maturation with particular reference to the boar. Journal of Reproduction and Fertility 53 99-107.

Dacheux JL, Castella S, Gatti JL \& Dacheux F 2005 Epididymal cell secretory activities and the role of proteins in boar sperm maturation. Theriogenology 63 319-341.

Dostalova Z, Calvete JJ, Sanz L \& Topfer-Petersen E 1994 Quantitation of boar spermadhesins in accessory sex gland fluids and on the surface of epididymal, ejaculated and capacitated spermatozoa. Biochimica et Biophysica Acta. General Subjects 1200 48-54.

Evans RW \& Setchell BP 1979 Lipid changes in boar spermatozoa during epididymal maturation with some observations on the flow and composition of boar rete testis fluid. Journal of Reproduction and Fertility 57 189-196.

Flesch FM, Brouwers JFHM, Nievelstein PFEM, Verkleij AJ, van Golde LMG, Colenbrander B \& Gadella BM 2001 Bicarbonate stimulated phospholipid scrambling induces cholesterol redistribution and enables cholesterol depletion in the sperm plasma membrane. Journal of Cell Science $1143543-3555$

Gadea J, Selles E \& Marco M 2004 The predictive value of porcine seminal parameters on fertility outcome under commercial conditions. Reproduction in Domestic Animals 39 303-308.
Garner D \& Johnson L 1995 Viability assessment of mammalian sperm using SYBR-14 and propidium iodide. Biology of Reproduction $\mathbf{5 3}$ 276-284.

Gilmore JA, Liu J, Peter AT \& Critser JK 1998 Determination of plasma membrane characteristics of boar spermatozoa and their relevance to cryopreservation. Biology of Reproduction 58 28-36.

Girouard J, Frenette G \& Sullivan R 2008 Seminal plasma proteins regulate the association of lipids and proteins within detergentresistant membrane domains of bovine spermatozoa. Biology of Reproduction 78 921-931.

Greube A, Muller K, Topfer-Petersen E, Herrmann A \& Muller P 2001 Influence of the bovine seminal plasma protein PDC-109 on the physical state of membranes. Biochemistry 40 8326-8334.

Greube A, Muller K, Topfer-Petersen E, Herrmann A \& Muller P 2004 Interaction of fibronectin type II proteins with membranes: the stallion seminal plasma protein SP-1/2. Biochemistry 43 464-472.

James PS, Wolfe CA, Ladha S \& Jones R 1999 Lipid diffusion in the plasma membrane of ram and boar spermatozoa during maturation in the epididymis measured by fluorescence recovery after photobleaching. Molecular Reproduction and Development 52 207-215.

Jonakova V, Manaskova P, Kraus M, Liberda J \& Ticha M 2000 Sperm surface proteins in mammalian fertilization. Molecular Reproduction and Development 56 275-277.

Jones R, James PS, Howes L, Bruckbauer A \& Klenerman D 2007 Supramolecular organization of the sperm plasma membrane during maturation and capacitation. Asian Journal of Andrology 9 438-444.

Klein T, Cooper TG \& Yeung CH 2006 The role of potassium chloride cotransporters in murine and human sperm volume regulation. Biology of Reproduction 75 853-858.

McClean R, MacCallum C, Blyde D, Holt WV \& Johnston SD 2006 Ultrastructure, osmotic tolerance, glycerol toxicity and cryopreservation of caput and cauda epididymidal kangaroo spermatozoa. Reproduction, Fertility, and Development 18 469-476.

Nikolopoulou M, Soucek DA \& Vary JC 1985 Changes in the lipid content of boar sperm plasma membranes during epididymal maturation. Biochimica et Biophysica Acta 815 486-498.

Noiles EE, Thompson KA \& Storey BT 1997 Water permeability, Lp, of the mouse sperm plasma membrane and its activation energy are strongly dependent on interaction of the plasma membrane with the sperm cytoskeleton. Cryo Letters 35 79-92.

Okada Y, Maeno E, Shimizu T, Dezaki K, Wang J \& Morishima S 2001 Receptor-mediated control of regulatory volume decrease (RVD) and apoptotic volume decrease (AVD). Journal of Physiology 532 3-16.

Petrounkina A, Harrison R, Petzoldt R, Weitze K \& Topfer-Petersen E 2000 Cyclical changes in sperm volume during in vitro incubation under capacitating conditions: a novel boar semen characteristic. Journal of Reproduction and Fertility 118 283-293.

Petrunkina AM, Harrison RAP, Ekhlasi-Hundrieser M \& Topfer-Petersen E 2004 Role of volume-stimulated osmolyte and anion channels in volume regulation by mammalian sperm. Molecular Human Reproduction 10 815-823.

Petrunkina AM, Gropper B, Topfer-Petersen E \& Gunzel-Apel A-R 2005 Volume regulatory function and sperm membrane dynamics as parameters for evaluating cryoprotective efficiency of a freezing extender. Theriogenology 63 1390-1406.

Petrunkina AM, Waberski D, Gunzel-Apel AR \& Topfer-Petersen E 2007a Determinants of sperm quality and fertility in domestic species. Reproduction 134 3-17.

Petrunkina AM, Harrison RAP, Tsolova M, Jebe E \& Topfer-Petersen E $2007 b$ Signalling pathways involved in the control of sperm cell volume. Reproduction 133 61-73.

Quinious N \& Noblet J 1995 Prediction of tissular body composition from protein and lipid deposition in growing pigs. Journal of Animal Science 73 1567-1575

Ramakrishnan M, Anbazhagan V, Pratap TV, Marsh D \& Swamy MJ 2001 Membrane insertion and lipid-protein interactions of bovine seminal plasma protein PDC-109 investigated by spin-label electron spin resonance spectroscopy. Biophysical Journal 81 2215-2225.

Rana AP \& Majumder GC 1990 Changes in the fluidity of the goat sperm plasma membrane in transit from caput to cauda epididymis. Biochemistry International 21 797-803. 
Rana AP, Majumder GC, Misra S \& Ghosh A 1991 Lipid changes of goat sperm plasma membrane during epididymal maturation. Biochimica et Biophysica Acta 1061 185-196.

Rodriguez-Martinez H 2006 State of the art in farm animal sperm evaluation. Reproduction, Fertility, and Development 19 91-101.

Schilling E \& Vengust M 1987 Frequency of semen collection in boars and quality of ejaculates as evaluated by the osmotic resistance of acrosomal membranes. Animal Reproduction Science 12 283-290.

Schweisguth DC \& Hammerstedt RH 1992 Evaluation of plasma membrane stability by detergent-induced rupture of osmotically swollen sperm. Journal of Biochemical and Biophysical Methods 24 81-94.

Stutzin A \& Hoffmann EK 2006 Swelling-activated ion channels: functional regulation in cell-swelling, proliferation and apoptosis. Acta Physiologica $18727-42$.

Syntin P, Dacheux F, Druart X, Gatti J, Okamura N \& Dacheux J 1996 Characterization and identification of proteins secreted in the various regions of the adult boar epididymis. Biology of Reproduction 55 956-974.

Tannert A, Topfer-Petersen E, Herrmann A, Muller K \& Muller P 2007 The lipid composition modulates the influence of the bovine seminal plasma protein PDC-109 on membrane stability. Biochemistry 46 11621-11629.

Watson PF 2000 The causes of reduced fertility with cryopreserved semen. Animal Reproduction Science 60-61 481-492.

Weibull WA 1951 A statistical distribution function of wide applicability. Journal of Applied Mechanics 18 293-297.
Yeung CH \& Cooper TG 2001 Effects of the ion-channel blocker quinine on human sperm volume, kinematics and mucus penetration, and the involvement of potassium channels. Molecular Human Reproduction 7 819-828.

Yeung $\mathrm{CH}$, Anapolski M, Sipila P, Wagenfeld A, Poutanen M, Huhtaniemi I, Nieschlag E \& Cooper TG 2002 Sperm volume regulation: maturational changes in fertile and infertile transgenic mice and association with kinematics and tail angulation. Biology of Reproduction 67 269-275.

Yeung CH, Anapolski M, Depenbusch M, Zitzmann M \& Cooper TG 2003 Human sperm volume regulation. Response to physiological changes in osmolality, channel blockers and potential sperm osmolytes. Human Reproduction 18 1029-1036.

Yeung CH, Anapolski M, Setiawan I, Lang F \& Cooper TG 2004 Effects of putative epididymal osmolytes on sperm volume regulation of fertile and infertile c-ros transgenic mice. Journal of Andrology 25 216-223.

Yeung CH, Barfield JP \& Cooper TG 2005 Chloride channels in physiological volume regulation of human spermatozoa. Biology of Reproduction 73 1057-1063.

Yeung CH, Barfield JP \& Cooper TG 2006 Physiological volume regulation by spermatozoa. Molecular and Cellular Endocrinology 250 98-105.

Received 22 May 2008

First decision 25 June 2008

Revised manuscript received 22 October 2008

Accepted 7 November 2008 